\title{
Co-Morbidity of Pituitary Adenoma and Frontal Convexity Meningioma: A Case Report and Review of the Literature
}

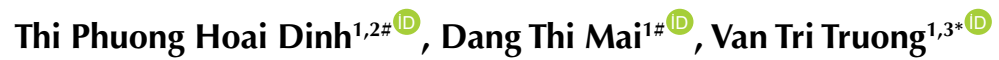 \\ ${ }^{1}$ Hue University of Medicine and Pharmacy - Hue University, Hue, Viet Nam \\ ${ }^{2}$ Online Research Club (http://www.onlineresearchclub.org/) \\ ${ }^{3}$ Division of Orthopedics, Central Hospital of University of Montreal, University of Montreal, Montreal, Canada
}

\begin{abstract}
Instruction: The current study reports a woman with pituitary adenoma and frontal convexity meningioma that was detected accidentally. To the best of our knowledge, this case is considered as a rare clinical scenario.

Case Presentation: A 37 years old woman suffering from amenorrhea and galactorrhea had her detail investigation showed hyperprolactinemia. The patient was diagnosed with a prolactinoma, and a frontal convexity meningioma was discovered on magnetic resonance imaging (MRI). The prolactinoma controlled with Bromocriptine therapy, while the meningioma monitored through medical observation. After two months of pharmaceutical medication, her symptoms improved with the decrease in serum prolactin.

Conclusion: Thanks to sophisticated MRI techniques, meningioma and prolactinoma were incidentally detected. It should be noted that co-morbidity of prolactinoma and meningioma is very rare. The mechanism of the association between these two familiar types of intracranial tumors has not yet been clarified, which indicates the need for further studies to offer possible targeted treatment for patients.

Keywords: Meningiomas; Prolactinomas; Pituitary adenomas.
\end{abstract}

*Correspondence to Truong Van Tri, Hue University of Medicine and Pharmacy - Hue University, Division of Orthopedics, Central Hospital of University of Montreal, University of Montreal, Montreal, Canada. E-mail: tvtri@huemed-univ.edu.vn

\#Authors equally contributed the work.

Published online June 21, 2020

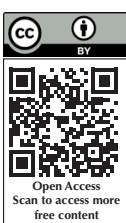

Citation: Dinh TPH, Mai DT, Truong VT. Co-Morbidity of Pituitary Adenoma and Frontal Convexity Meningioma: A Case Report and Review of the Literature. Clin Neurosci J. 2020;7(3):153-155. doi:10.34172/icnj.2020.17.

\section{Introduction}

Meningiomas are the most common primary intracranial tumors with an incidence of 6 cases per $100000 .^{1}$ Intracranial tumors arise from meningothelial cells of the arachnoid membrane that surrounds the central nervous system. The resulted lesions are usually benign, slowgrowing, and circumscribed. Its main risk factors include ionizing radiation, and neurofibromatosis type 1 (NF1). ${ }^{2}$ Prolactinomas represent the most common subtypes with $25 \%-41 \%$ of total pituitary adenomas in adults. ${ }^{3}$ Regarding that according to the recent studies prevalence of hyperprolactinemia is increasing, special attention is paying to this type of tumor. ${ }^{4}$

Several cases of meningioma developed after radiation therapy of pituitary adenomas are reported. ${ }^{5}$ However, the concomitant occurrence of these neoplasms is rare. In this regard, currently, six case report studies are published..$^{6-9}$ Considering the rarity of this co-morbidity, another case of simultaneous occurrence of frontal meningioma and prolactinoma is reported in the current study. As well, a discussion about the clinical presentation, imaging features and management of this rare condition is provided.

\section{Case Presentation}

A 37 years old Asian woman presented at the out-patient clinic with an episode of amenorrhea, galactorrhea, and vaginal dryness (for the past 10 months). During the physical examination, there was no sign of neurological disorders. There was no abnormality in her medical records. She had two vaginal delivery without postpartum complications. Initial laboratory workups showed that all of her endocrinological hormones are in normal range except for hyperprolactinemia that was $2122 \mathrm{uUI} / \mathrm{mL}$ (normal range 102-496 uIU/mL).

Moreover, MRI revealed a lesion of $2 \times 2 \mathrm{~mm}$ in diameter at the posterior pituitary, T1W and T2W isointense (Figure 1), and an extra-axial lesion of $14 \times 9$ $\mathrm{mm}$ with a dural tail sign, T1W iso-intense, T2W hypointense, homogeneous enhancement on T1 Gd located 


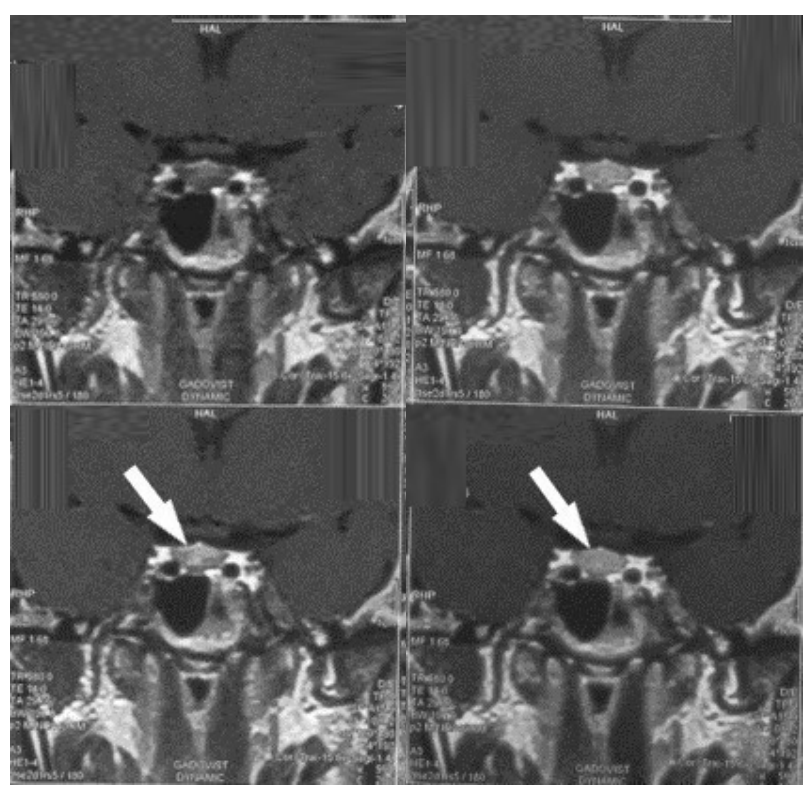

Figure 1. Left: The parenchyma of the pituitary gland, below the pituitary pedicle, has a lesion $2 \times 2 \mathrm{~mm}$ in diameter at the posterior pituitary, slight restricted diffusion is seen on T1W dynamic. Right: The parenchyma of the pituitary gland on T1W and $\mathrm{T} 2 \mathrm{~W}$ iso-intense on post-contrast study (white arrow).

at the right frontal lobe (Figure 2). Diagnostic processes revealed that the patient had both a prolactinoma and a right convexity meningioma.

The prolactinoma was managed with pharmaceutical medication. The medication began with oral Bromocriptine (Parlodel ${ }^{\circ}$ ) $2.5 \mathrm{mg}$ with 1 tablet daily for 2 months. To treat convexity meningioma, due to the size and asymptomatic condition, surgery was not recommended. After 2 months of treatment, the dose of serum prolactin decreased to $1535 \mathrm{uUI} / \mathrm{mL}$. Menstrual cycles and sexual functions were normalized. As well, galactorrhea also decreased. Monthly follow-ups, including serum prolactin test, are necessary. The dosage of oral Bromocriptine would be adjusted in accordance with serum prolactin. Meanwhile, the meningioma was monitored by using clinical symptoms. To Monitor the progression of both tumors, MRI would be performed 6 months after the initial observation.

\section{Discussion}

The simultaneous occurrence of meningioma and prolactinoma is rare. The authors could find six studies that were related to this area (Table 1), which all were reviewed. Both males and females were investigated by these studies. Also, meningiomas were located in different locations.

Fortuitously, the results of the MRI that was performed to diagnosis prolactinomas revealed several meningiomas. Technically, histological examination should be performed to confirm the diagnosis of meningiomas.
However, signal characteristics obtained from the MRI images (dura tail sign, T1W iso-intense, T2W hypointense, homogeneous enhancement on T1 Gd) (Figure 2) were acceptable. Therefore, versatile imaging technique such as MRI would be helpful, particularly for diagnostic procedures of concomitant intracranial lesions.

There are three possible reasons to explain pituitary adenomas associated with meningioma, including: by chance occurrence, the impact of environmental factors, or genetic predisposition. Currently, the exact association between meningioma and pituitary adenoma has not been elucidated. ${ }^{10}$

Recent studies reported that prolactin stimulates the proliferation of human meningioma cells in vitro, and a possible impact of prolactin in the growth of meningioma is suggested. ${ }^{11,12}$ Also, there are studies that reviewed meningiomas cases which were developed after radiation. ${ }^{13}$ Since there was no history of radiation or familial-related diseases in the present patient, the occurrence of these two intracranial tumors may be coincidental. However, the possibility of meningioma caused by high levels of serum prolactin should not be ignored, because human meningiomas express functional receptors for prolactin which are involved in mediating its proliferative effect. ${ }^{12}$

To manage meningioma, the Endocrine Society Clinical Practice Guideline recommended administration of dopamine agonist in patients with pituitary microadenomas (prolactinoma) who have amenorrhea. ${ }^{14}$ Our patient had her follow-up after 2 months of using Bromocriptine with the resolution of previous symptoms and a decrease in serum prolactin, from $2122 \mathrm{uUI} / \mathrm{mL}$ to $1535 \mathrm{uUI} / \mathrm{mL}$. Regarding that the patient well-responded to Bromocriptine therapy, surgical treatment is not recommended. Concerning the meningioma, according to EANO guidelines, since there was no mass effect and symptoms, observational management was chosen. ${ }^{15}$ The exact association between prolactinoma and meningioma was not proposed due to the rarity of this co-morbidity.

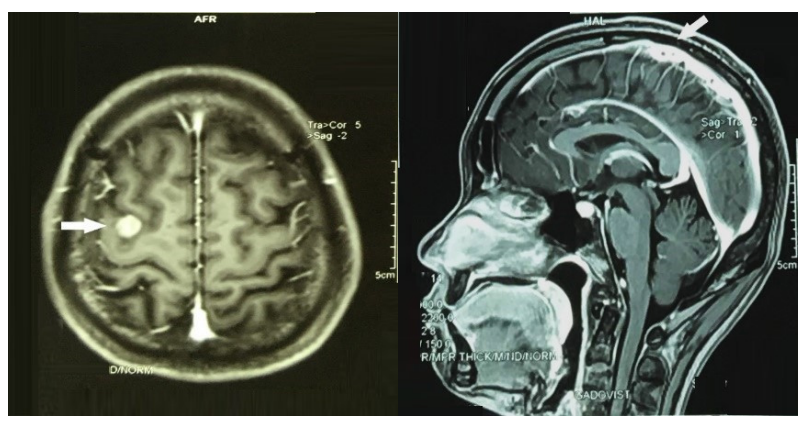

Figure 2. Left: postcontrast axial T1-weighted MR Image of the brain demonstrating an anterior parasagittal meningioma located at the right frontal lobe. Right: postcontrast sagittal T1-weighted MR Image an extra-axial lesion in $14 \times 9 \mathrm{~mm}$ with dural tail sign $\mathrm{T} 1 \mathrm{~W}$ iso-intense, T2W hypo-intense homogeneous enhancement in T1 Gd (white arrow). 
Table 1. Summary of Reported Cases in the Literature

\begin{tabular}{|c|c|c|c|c|c|c|}
\hline No. & Study & Sex & Age & Pituitary Adenoma & Meningioma Site & Management \\
\hline 1 & Zentner et $\mathrm{al}^{8}$ & M & 46 & Prolactinoma & Planum sphenoidale & Resection \\
\hline 2 & Görge et $\mathrm{al}^{9}$ & M & 53 & Prolactinoma & Para- and suprasellar & Resection \\
\hline 3 & Abs et $\mathrm{al}^{6}$ & $\mathrm{~F}$ & 47 & Prolactinoma & Tuberculum sellae & Resection \\
\hline 4 & Abs et $\mathrm{al}^{6}$ & $\mathrm{~F}$ & 45 & Prolactinoma & Temporal fossa & No surgery \\
\hline 5 & Abs et $\mathrm{al}^{6}$ & $\mathrm{~F}$ & 61 & Prolactinoma & Choroid plexus & No surgery \\
\hline 6 & Amirjamshidi et $\mathrm{al}^{7}$ & $\mathrm{~F}$ & 37 & Prolactinoma & Suprasellar & Resection \\
\hline 7 & Present case & $\mathrm{F}$ & 37 & Prolactinoma & Frontal convexity & No surgery \\
\hline
\end{tabular}

Instead of applying specific targeted treatment for both tumors, decisions regarding the treatment of the patient were made separately depending on each tumor clinical manifestation. However, a study in 1997 suggested new therapeutic strategies such as prolactin-receptor antagonist. ${ }^{12}$ Therefore, further studies are required to specify the management protocol for patients with these two types of intracranial tumors. Follow-up care involves monthly serum prolactin measurement. In addition, MRI should be performed 6 months after the initial treatment to re-evaluate both tumors. ${ }^{15}$

\section{Conclusion}

Thanks to sophisticated MRI techniques, meningioma and prolactinoma were incidentally detected. Clinical monitoring for each tumor was applied separately, because the association between these two types of intracranial tumors were not clarified, which indicate the need for further studies to propose targeted treatment for such patients.

\section{Conflict of Interest}

The authors declare that they have no conflict of interests.

\section{Ethical Statement}

This study was approved by the ethical approval committee/ Institutional Review Board of Hue University of Medicine and Pharmacy, No. 2375 / QD-DHYD, March 18, 2020.

\section{Reference}

1. Furtado SV, Venkatesh PK, Ghosal N, Hegde AS. Coexisting intracranial tumors with pituitary adenomas: genetic association or coincidence? J Cancer Res Ther. 2010;6(2):2213. doi: 10.4103/0973-1482.65246.

2. Simon M, Boström JP, Hartmann C. Molecular genetics of meningiomas: from basic research to potential clinical applications. Neurosurgery. 2007;60(5):787-98. doi: 10.1227/01.neu.0000255421.78431.ae.

3. Ezzat S, Asa SL, Couldwell WT, Barr CE, Dodge WE, Vance $\mathrm{ML}$, et al. The prevalence of pituitary adenomas: a systematic review. Cancer. 2004;101(3):613-9. doi: 10.1002/cncr.20412.

4. Soto-Pedre E, Newey PJ, Bevan JS, Greig N, Leese GP. The epidemiology of hyperprolactinaemia over 20 years in the
Tayside region of Scotland: the Prolactin Epidemiology, Audit and Research Study (PROLEARS). Clin Endocrinol (Oxf). 2017;86(1):60-7. doi: 10.1111/cen.13156.

5. Umansky F, Shoshan Y, Rosenthal G, Fraifeld S, Spektor S. Radiation-induced meningioma. Neurosurg Focus. 2008;24(5):E7. doi: 10.3171/foc/2008/24/5/e7.

6. Abs R, Parizel PM, Willems PJ, Van de Kelft E, Verlooy J, Mahler $\mathrm{C}$, et al. The association of meningioma and pituitary adenoma: report of seven cases and review of the literature. Eur Neurol. 1993;33(6):416-22. doi: 10.1159/000116986.

7. Amirjamshidi A, Mortazavi SA, Shirani M, Saeedinia S, Hanif $\mathrm{H}$. 'Coexisting pituitary adenoma and suprasellar meningioma-a coincidence or causation effect: report of two cases and review of the literature'. J Surg Case Rep. 2017;2017(5):rjx039. doi: 10.1093/jscr/rjx039.

8. Zentner J, Gilsbach J. Pituitary adenoma and meningioma in the same patient. Report of three cases. Eur Arch Psychiatry Neurol Sci. 1989;238(3):144-8. doi: 10.1007/bf00451002.

9. Görge HH, Pöll W, Gers B. [Para- and suprasellar meningioma coincident with a hormonally active intrasellar hypophyseal adenoma--case report]. Zentralbl Neurochir. 1993;54(4):1906.

10. Zhu H, Miao Y, Shen Y, Guo J, Xie W, Zhao S, et al. The clinical characteristics and molecular mechanism of pituitary adenoma associated with meningioma. J Transl Med. 2019;17(1):354. doi: 10.1186/s12967-019-2103-0.

11. Jimenez-Hakim E, el-Azouzi M, Black PM. The effect of prolactin and bombesin on the growth of meningioma-derived cells in monolayer culture. J Neurooncol. 1993;16(3):185-90. doi: 10.1007/bf01057032.

12. Muccioli G, Ghè C, Faccani G, Lanotte M, Forni M, Ciccarelli E. Prolactin receptors in human meningiomas: characterization and biological role. J Endocrinol. 1997;153(3):365-71. doi: 10.1677/joe.0.1530365.

13. Spallone A. Meningioma as a sequel of radiotherapy for pituitary adenoma. Neurochirurgia (Stuttg). 1982;25(2):6872. doi: 10.1055/s-2008-1053960.

14. Melmed S, Casanueva FF, Hoffman AR, Kleinberg DL, Montori VM, Schlechte JA, et al. Diagnosis and treatment of hyperprolactinemia: an Endocrine Society clinical practice guideline. J Clin Endocrinol Metab. 2011;96(2):273-88. doi: 10.1210/jc.2010-1692.

15. Goldbrunner R, Minniti $G$, Preusser $M$, Jenkinson $M D$, Sallabanda K, Houdart E, et al. EANO guidelines for the diagnosis and treatment of meningiomas. Lancet Oncol. 2016;17(9):e383-91. doi: 10.1016/s1470-2045(16)30321-7. 